\title{
Familieterapi, systemteori og selvmordsatferd
}

\author{
Ved Berit Grøholt
}

\begin{abstract}
Familieterapi har en relativt kort historie i terapeutisk barnearbeid. I 20-årene ble problembarnet brakt alene til terapeut. Etter hvert snakket man med foreldrene om barnet, og noe senere snakket man til foreldrene om hvordan de skulle vaere mot barna. Det neste var at alle familiemedlemmene fikk hver sin terapeut, slik man praktiserte det i 50-årene. I 60-årene hadde man gjerne barnet i terapi mens foreldrene gikk til felles samtaler. Først for omtrent 30 år siden møtte man familemedlemmene sammen, og familieterapien tok form.
\end{abstract}

Bakgrunnen for denne utviklingen er erkjennelsen av at enhver plage hos et familiemedlem vil påvirke de andre i familien. Forandringene hos en vil nødvendigvis skape sekundære forandringer hos de andre.

\section{Hva er systemteori?}

Denne oppfatningen tok utgangspunkt i nye teoretiske modeller fra naturvitenskapene. Antropologen Bateson ble inspirert av kybernetikk (læren om de regulerende og selvregulerende systemer) hentet fra teknikken, og systemteori hentet fra biologien (Bertalanffy 1956). Han (Bateson 1973) beskrev familien som et system som kan sammenlignes med en dampmaskin med ventil. Når damptrykket stiger, vil kreftene påvirke ventilen slik at damp slipper ut, og når trykket synker, vil ventilen igjen lukke systemet. Vi får et vedvarende samspill med feedback (eller utveksling av informasjon) mellom damptrykk og ventil. Brukt på menneskelige systemer blir modellen mer komplisert, og faktorer som personer, hendelser og holdninger spiller inn. Informasjon (i videste forstand) som utveksles mellom faktorene styrer deres innbyrdes sammenheng. Avsender og mottager av informasjon er like viktige i denne prosessen. Vi kan ikke benytte vanlig årsak/virkningtenkning. Vi må se de enkelte faktorene snart som årsak, snart som virkning i et vedvarende vekselspill. Overført til familien kan vi si at reglene for hva slags informasjon som utveksles mellom familiemedlemmene, bestemmer hvilke av de iboende muligheter for atferd det enkelte familiemedlem kan vise. Reglene vil også påvirke hvordan en gitt atferd blir oppfattet. I kybernetikken er det et mål å opprettholde likevekt (kfr. dampmaskinen). Et symptom kan slik sett være et fors $\varnothing \mathrm{k}$ på å opprettholde likevekt i et system der balansen er truet. Et eksempel kan være det uregjerlige barnet som trekker oppmerksomhet bort fra foreldrenes konflikt og derved bidrar til å holde familien sammen. Denne måten å se familien på har fått gjennomslagskraft, og systemteori preger det meste av familieterapeutiske arbeid. Familien er blitt et naturlig utgangspunkt for terapi når man vil forsøke å endre symptomatferd hos barn.

\section{Utviklingen i 90-årene}

Mye har skjedd siden Batesons tanker for alvor fikk gjennomslag. Mange er påvirket av postmodernistisk tenkning: Alt er blitt så komplisert at helheten ikke lar seg overskue. Allikevel forstår vi viktige hendelser og følelser i våre liv på en slik måte at det gir mest mulig mening for oss. Nye hendelser eller informasjon kan rikke på mønstret slik at vi plutselig ser fortidens hendelse i et nytt lys: Vi kan skape en annerledes og ny historie om oss selv, eller om familien vår. Et nytt "narrativ" sier mange familieterapeuter med et ord fra lånt fra litteraturvitenskapen. En postmodernist vil hevde at ingen kan si at én historie er gal, og en annen riktig: All vår forståelse er i bunn og grunn konstruksjoner. På bakgrunn av en slik tankegang har begreper som konstruktivisme og narrative terapiteknikker slått rot (Hoffman 1987). Alle disse nye begrepene er skapt innenfor rammen av systemteori. Felles er at den tradisjonelle forståelse om et en hendelse er årsak til en annen (lineær tankegang) blir forkastet, og fors $\varnothing \mathrm{kt}$ erstattet med sirkulær eller systemisk forståelse.

\section{Lineaer og sirkulaer forståelse}

Vi vil se nærmere på forskjellen mellom lineær og sirkulær tankegang. I vår del av verden har vi som tradisjon å tenke i årsak og virkning, vi deler opp våre opplevelser i sekvenser med begynnelse og slutt. "Far kritiserer mor. Mor blir lei seg." Dette er en lineær tankegang. Forestillingen om at far gjør mor lei seg, fører lett til idéen om at far har til hensikt å gjøre mor lei seg, og en moralsk vurdering farger lett oppfatningen av familiesamhandlingene. Hvis vi fjerner våre sedvanlige "punktum", vil vi kanskje se at når mor er lei seg, blir barnet uskikkelig, og når barnet er uskikkelig, kritiserer far mor. Når far kritiserer, blir mor lei seg, og når mor blir lei seg ... osv. Terapeuten har en sirkulær tankegang og flytter fokus fra enkeltpersoner til relasjoner og handlingsm $\varnothing$ nstre. Det fører i seg selv til mindre moralisme, man blir mer opptatt av effekten av handlinger enn av intensjonen.

\section{Familieterapi}

I dag er familieterapi et sentralt element i barnepsykiatrisk arbeid. Men vårt samfunn er gjennomsyret av lineær årsakvirkning-tenkning, ikke minst når det gjelder selvmord og selvmordsfors $\varnothing \mathrm{k}$. Familier med vanskelige barn møter det stadig: Hva for noe galt har foreldrene gjort? De fleste foreldre stiller seg selv spørsmålet med stor kraft: Hvor sviktet jeg? For noen kan et tilbud om familieterapi virke som en bekreftelse på skyld. Følelsen av skyld er nesten alltid tilstede når en kjær person lider: Kjærlighet og skyldfølelse er som lys og skygge, der gode $\varnothing$ nsker ikke hjelper, oppleves lett skyld, uavhengig av hva foreldre har gjort. Selvsagt har alle foreldre gjort mye som er kritikkverdig (sier de at de er hevet over kritikk, er det iallfall kritikkverdig). Men - i familieterapi er ikke årsak eller skyld på dagsorden. Vi leter etter forhold som kan skape endring der familien $\varnothing$ nsker endring, enten det er utagering, selvskading eller en hvilken som helst sykdom. Det er ikke "de skyldige", men de med mest overskudd som best kan delta i forandringsprosesser. Hvis familien har så store belastninger at barnets sentrale behov ikke kan møtes, er ikke terapi tilstrekkelig. Da må andre st $\varnothing$ ttetiltak til, i eller utenfor familien. 


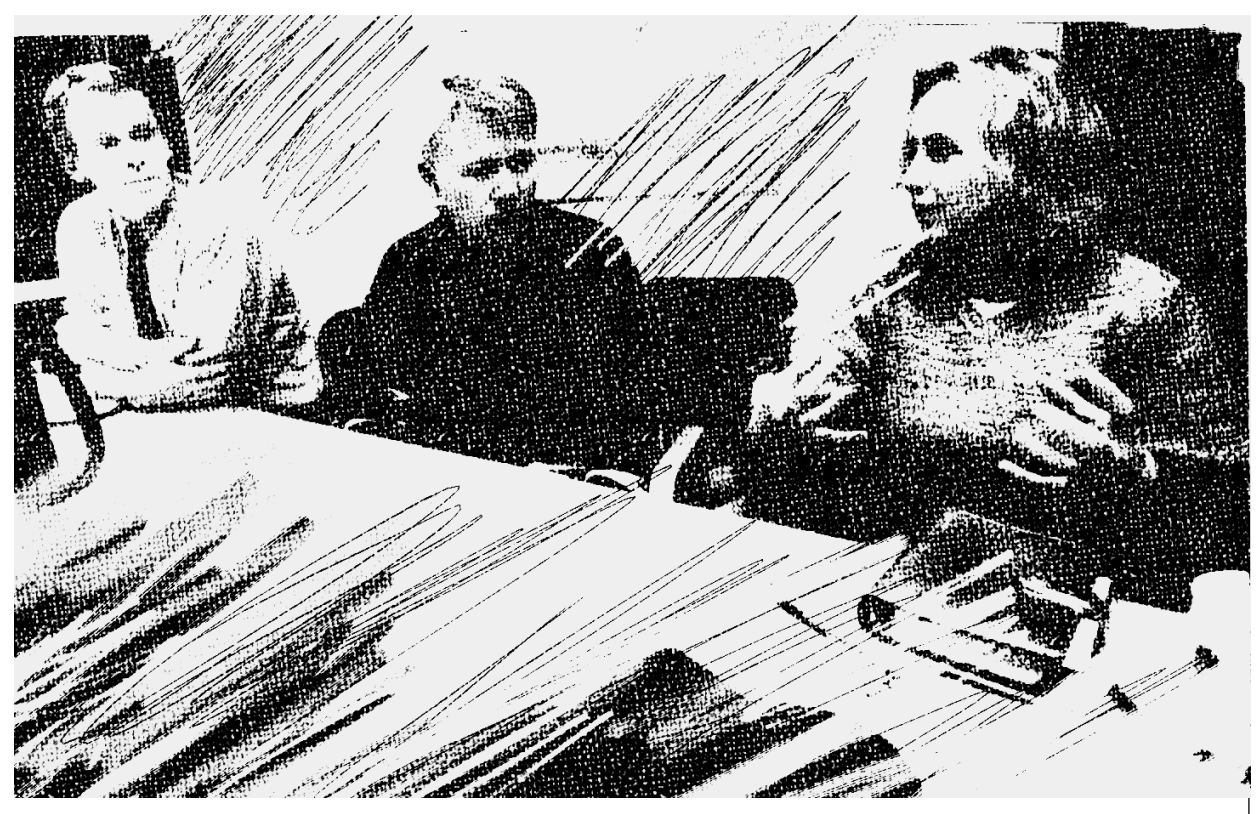

\section{Familieterapi og selvmords- atferd blant barn og unge}

Når det gjelder selvmordsatferd vet vi at bildet er så sammensatt at en forklaring aldri er rett. En behandlingsmåte er også sjelden tilstrekkelig. Vi vet at den naturlige skyldfølelsen kan bli sterk, nesten uutholdelig, og blandes med angst eller sinne. Tilbud om familieterapi kan i første omgang forsterke disse følelsene. Allikevel er alle som arbeider med selvmordsproblematikk hos barn og unge, enige om en ting: Familien må involveres på en eller annen måte (King et al. 1997). Familien trenger hjelp og støtte for egen del, og ennå mer for å være en støtte for barnet sitt. Konfliktnivået er også ofte høyt i familier der én er selvmordstruet. Hva vi gjør i praksis, bør skje på bakgrunn av diskusjon mellom familiene og hjelperne. Vi hjelpere kan ikke med hånden på hjertet si at dette hjelper, men det hjelper ikke. Behandlingen må passe til familiens behov og ønsker. Men profesjonelle hjelpere må hente erfaring fra forskning, fra andre erfarne terapeuter, og fra egen erfaring, og gi anbefalinger utfra det. Faglig kunnskap, for eksempel om psykiatrisk lidelse og selvmord, må tas med som et viktig element i systemet. Som behandlere er vi også en del av et system, og den informasjonen vi gir, kan påvirke familiens opplevelse av si egen historie.

\section{Klinisk eksempel:}

Liv, 15 år, har i lang tid vært stille og innadvendt, og livredd for ikke å strekke til. Moren har blitt meget beskyttende, mens faren har stilt klare krav til henne, noe som har ført til protester fra mor. Dette har gjort Liv ennå mer skyldbetynget. Foreldrene er sjelden høyrøstet, men Liv værer lett den minste misstemning i huset. En dag, uten noen ytre foranledning, tok Liv en stor dose tabletter i suicidal hensikt - for som hun skrev - hun gjorde livet bare verre for de hun var glad i. Men hun greide seg uten skader, og kom snart i behandling for depresjon.

Hun ble lettere, men hjemme var misstemningen til å ta og føle på, mente Liv. Legen hennes foreslo familieterapi. Her ble alle bedt om å si hva de $\varnothing$ nsket annerledes: Liv $\varnothing$ nsket gladere foreldre, hun mente de stadig ble

tausere sammen. Moren gikk på tå hev for Liv, og var redd for at hun skulle si noe som kunne gjøre Liv suicidal. Det $\varnothing$ nsket hun annerledes. Faren oppfattet at moren ga han skylden for Livs problemer. Han $\varnothing$ nsket at de kunne få anklagene på bordet, og bli ferdig med det. Alle tre var overrasket over de andres perspektiv. Først fikk alle informasjon om depresjon, bl.a. mulighet for tilbakefall (psykoedukativ tilnærming). Liv ønsket selv ansvaret for å si fra hvis hun igjen ble deprimert. Varseltegn ble drøftet, og en avtale inngått om at alle kunne kontakte hverandre hvis de mente at Liv ikke sa fra når hun burde. Dette fritok mor for noe av engstelsen.

Foreldrene fikk i oppgave å snakke sammen minst to ganger hver uke, og plassere sin engstelse for Liv på en skala fra 0 til 10. Ved neste avtale fortalte moren overrasket at faren var minst like redd som henne. For dem hadde det vært godt å snakke sammen om dette. Tema denne timen var: Hvem føler seg anklaget av hvem? Moren hadde alltid følt seg skyldig fordi hun var borte fra Liv 4 uker da hun var 2 år. Far sa at han var handlingslammet fordi alt han gjorde var "mas" og skadet Liv. Til slutt slo Liv i bordet - nesten - fordi alle ville ha "skylda" for hennes selvskade. Den ville hun ha selv. Hun tålte godt mas, selv om hun ikke alltid likte det. Det er bare bra at foreldre er forskjellige. Men hun følte seg skyldig i å ha ødelagt foreldrenes forhold.

Etter noen timer til hadde mye blitt annerledes. Foreldrene ble begge mer aktive. De var forskjellige, og det kunne skape misstemning, men de forbeholdt seg retten til å være litt sure, og synes ikke Liv skulle blande seg i det. De snakket mer sammen. Etter ytterligere noen måneder kunne hele familien 


\section{Selvmord blant barn og ungdom - to norske arbeider}

Selvmordsraten i Norge var 1990-92 18,6 pr 100.000 pr. år for gutter i alderen 15-19 år og 6,3 for jenter. For barn i alderen 10-14 år var den 2,7 for gutter og 0,5 for jenter. I to viktige arbeider har en gått gjennom alle selvmord blant barn og unge i Norge i denne perioden.

I det første arbeidet (Grøholt et al. 1997) gikk forfatteren gjennom alle suicid registrert i disse aldersgruppene ( $\mathrm{N}=129)$ og sammenliknet med en alders- og kjønnsjustert kontrollgruppe. Som hovedrisikofaktorer fant de depresjon, atferdsvansker og tidligere selvmordsfors $\varnothing \mathrm{k}$. Av dem som hadde tatt livet sitt, hadde 74 \% fătt diagnostisert psykiatrisk sykdom. Suicidal hensikt var uttrykt hos $48 \%$, men få (24 \%) hadde fått behandling til tross for et velutviklet helsetilbud. En sykehistorie med atferdsavvik (17 \%) og stoffmisbruk (10\%) ble funnet mindre hyppig enn i tidligere arbeider, men overdreven drikking i form av fylleslag, kan ha vært av betydning i flere tilfeller.

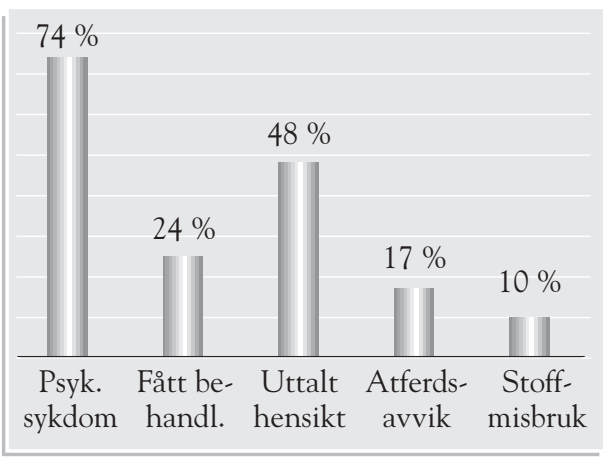

Depresjon pekte seg ut som en særlig viktig risikofaktor. Det å ikke bo sammen med to biologiske foreldre ga imidlertid ikke $\varnothing \mathrm{kt}$ risiko for selvmord med mindre ungdommen også hadde en affektiv lidelse eller atferdsvansker. Henging og skyting var de mest anvendte metoder hos begge kjønn. Forfatterne fremhever betydningen av å nå frem med behandling til ungdom med depresjon, og også å ta alvorlig uttrykt suicidal hensikt.

I det andre arbeidet (Grøholt et al 1998) sammenlikner forfatterne egenskaper og risikofaktorer ved selvmord hos barn og unge under 15 år $(\mathrm{N}=14)$ med tilsvarende hos ungdom 15-19 år $(\mathrm{N}=115)$. Det ble samlet informasjon fra mange kilder om disse ungdommene, som alle tok sitt eget liv i Norge i 3-årsperioden 1990-92. Disse sammenliknes også med ei kontrollgruppe ( $\mathrm{N}=899)$ matched for kjønn og alder. De yngste (under 15 år) tok hyppigere livet sitt ved henging enn de eldre (93 $\%$ mot $35 \%$ ). Selvmordstanker (7 \% mot $39 \%$ ) og utløsende livsbegivenheter ble beskrevet sjeldnere (29\% mot $49 \%$ ) hos de yngste. De eldste (15-19 år) hadde hyppigere psykiske lidelser (77 \% mot $43 \%$ ). Sammenliknet med kontrollgruppen var affektive lidelser, atferdsvansker og det forhold at man ikke lever sammen med to foreldre risikofaktorer for suicid $i$ begge gruppene.

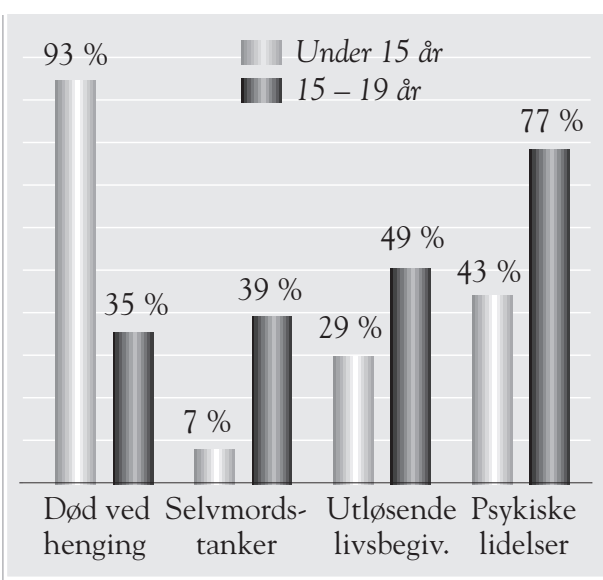

I den yngste aldersgruppen var ungdommer som tok livet sitt, mindre utsatt for kjente risikofaktorer sammenliknet med gruppen 15-19 år. Den $\varnothing$ kte selvmordsrisikoen var lik for begge grupper når de ble sammenliknet med kontrollgruppen. Den lave selvmordshyppigheten hos barn kan henge sammen med færre risikofaktorer heller enn med at de har en større motstandsevne overfor risikofaktorer.

Grøholt B, Ekeberg $\varnothing$, Wickstrøm L,

Haldorsen T: Youth suicide in Norway, 1990 1992: a comparison between children and adolescents completing suicide and age- and gender-matched controls. Suicide and lifethreatening behavior 1997; 27: 250-263

Grøholt B, Ekeberg $\varnothing$, Wichstrøm L, Haldorsen T: Suicide among children and younger and older adolescents in Norway. A comparative study. J. Am. Acad. Child Adolesc. Psychiatry 1998; 37: 473-481

Nils Retterst $\varnothing 1$
Fortsatt fra forrige side

spøke med den tiden da alle sloss om å være skyldige. (De hadde fått en ny historie om seg selv.) De hadde alle gitt seg selv større handlingsrom, og en misstemning var ikke lenger noen katastrofe. Uansett hva framtiden ville bringe, hadde de et større repertoar for å møte nye vansker.

\section{Konklusjon:}

Familien bør alltid involveres når unge har skadet seg selv. Kunnskapsformidling til familien er viktig. Familieterapeutisk tilnærming for å redusere konfliktnivå bør ofte kombineres med individuell tilnærming til den unge.

\section{Litteratur}

Bateson, G. Steps to an ecology of mind. St. Albans: Paladin, 1973.
Bertalanffy, L.v. General Systems Theory General Systems Yearbook, 1956.

Brent, D.A. The aftercare of adolescents with deliberate self-harm. Journal of child psychology and psychiatry 1997a; 38 (3) : 277-286.

Brent, D.A., Holder, D., Kolko, D., Birmaher, B., Baugher, M., Roth, C., Iyengar, S., \& Johnson, B.A. A clinical psychotherapy trial for adolescent depression comparing cognitive, family, and supportive therapy. Archives of general psychiatry 1997b; 54 (9) : 877-885.

Brent, D.A., Poling, K., McKain, B., \& Baugher, M. A psychoeducational program for families of affectively ill children and adolescents. Journal of the American Academy of child and adolescent psychiatry 1993; 32 (4): 770-774.

Hoffman, L. La oss legge makt og kontroll bak oss: mot en '2.ordens' systemisk familieterapi. Fokus på familien 1987; 15: 129-45.
King, C.A., Hovey, J.D., Brand, E., Wilson, R. $\&$ Ghaziuddin, N. Suicidal adolescents after hospitalization: parent and family impacts on treatment follow-through. Journal of the American Academy of child and adolescent psychiatry 1997; 36 (1) : 85-93.

Spirito, A. Family therapy techniques with adolescent suicide attempters.

Crisis 1997; 18 (3) : 106-109.

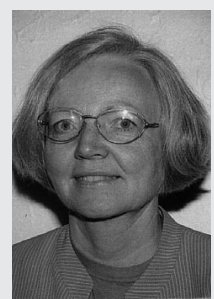

Berit Grøholt er barnepsykiater og har i mange år arbei det som overlege ved Sentral sykehuset i Akershus. De siste årene har hun vært forskningsstipendiat og senere universitetslektor ved Senter for barne- og ungdomspsykiatri.

Selvmord og selvmordsfors $\varnothing \mathbf{k}$ hos personer under 20 år har vært fokus i forskningen hennes. 